\title{
Preparation and Characterization of Latex Particles as Potential Physical Shale Stabilizer in Water-Based Drilling Fluids
}

\author{
Junyi Liu, Zhengsong Qiu, Wei’an Huang, Dingding Song, and Dan Bao \\ College of Petroleum Engineering, China University of Petroleum, Qingdao 266580, China \\ Correspondence should be addressed to Zhengsong Qiu; upcdrillingmud@sina.com
}

Received 8 May 2014; Accepted 5 June 2014; Published 23 June 2014

Academic Editor: Wenjun Jiang

Copyright (c) 2014 Junyi Liu et al. This is an open access article distributed under the Creative Commons Attribution License, which permits unrestricted use, distribution, and reproduction in any medium, provided the original work is properly cited.

\begin{abstract}
The poly(styrene-methyl methacrylate) latex particles as potential physical shale stabilizer were successfully synthesized with potassium persulfate as an initiator in isopropanol-water medium. The synthesized latex particles were characterized by Fourier transform infrared spectroscopy (FT-IR), particle size distribution measurement (PSD), transmission electron microscopy (TEM), and thermal gravimetric analysis (TGA). FT-IR and TGA analysis confirmed that the latex particles were prepared by polymerization of styrene and methyl methacrylate and maintained good thermal stability. TEM and PSD analysis indicated that the spherical latex particles possessed unimodal distribution from $80 \mathrm{~nm}$ to $345 \mathrm{~nm}$ with the D90 value of $276 \mathrm{~nm}$. The factors influencing particle size distribution (PSD) of latex particles were also discussed in detail. The interaction between latex particles and natural shale cores was investigated quantitatively via pore pressure transmission tests. The results indicated that the latex particles as potential physical shale stabilizer could be deformable to bridge and seal the nanopores and microfractures of shale to reduce the shale permeability and prevent pore pressure transmission. What is more, the latex particles as potential physical shale stabilizer work synergistically with chemical shale stabilizer to impart superior shale stability.
\end{abstract}

\section{Introduction}

In the past decade, shale gas, as a clean and unconventional energy, has become progressively important in the energy landscape worldwide [1-5]. In drilling engineering, wellbore instability in shale, such as hole collapse, tight hole, and lost circulation, has still been a challenge especially in horizontal drilling process due to fluid penetration of water-based drilling fluids into shale matrix and subsequent pore pressure build-up and sloughing of the wellbore [6-8]. Generally, oilbased drilling fluids were chosen to drill in shale formation because of no chemical interaction between oil and shale [9]. However, the increasingly stringent environmental and economic requirements restricted its wide use and specially designed water-based drilling fluid would be an alternative. Maintaining wellbore stability using water-based drilling fluid could be achieved by sealing/consolidating wellbore physically or chemically to prevent pore pressure transmission $[10,11]$. Recently, many solutions have been proposed for plugging the formation through different mechanisms, such as calcium carbonate, asphaltenes, polyglycols, and polymers, but only marginal success has been achieved $[12,13]$. Geologically, gas shales, a sedimentary rock, are mainly composed of clay-sized particles and are believed to be the low porosity and ultralow permeability reservoir with a significant pore volume in the nanopore range [14-16]. But conventional particles are too large to bridge and seal nanoscale pore throats and microfractures of shale and novel plugging agents in nanoscale are needed for shale stability.

Historically, emulsion polymerization was widely used in the preparation of polymer materials, especially nanomaterials, but the water resistance and surface smoothness of polymers were influenced inevitably by residual emulsifiers [17, 18]. The emulsifier-free emulsion polymerization emerged at the right moment $[19,20]$, and polymers could be synthesized without emulsifiers or just with small amount under critical micelle concentration (CMC). But it was too difficult to control the particles size and improve the conversion rate and 
stability of emulsifier-free latex [21]. Recently, solvothermal method has been applied to emulsifier-free polymerization [22], and high reacting temperature and reacting pressure could make it possible to decrease particle size and improve the stability of emulsifier-free latex.

In this work, the emulsifier-free latex particles as potential physical shale stabilizer in water-based drilling fluids were synthesized by emulsifier-free emulsion polymerization of styrene (St) and methyl methacrylate (MMA) using solvothermal method with potassium persulfate as an initiator in isopropanol-water medium. The newly synthesized latex particles were characterized in detail and the influencing factors on particle size distribution (PSD) of latex particles, such as isopropanol volume, reacting temperature, and initiator concentration, were also discussed. Moreover, the interaction between latex particles and natural shale cores was investigated quantitatively via pore pressure transmission tests.

\section{Experimental Materials and Methods}

2.1. Materials. The monomers of styrene (St) and methyl methacrylate (MMA), obtained from Sinopharm Chemical Reagent Co. Ltd. (China), were distilled under vacuum before use. The initiator, potassium persulfate, was obtained from Aladdin Reagent Co. Ltd. (China) and was recrystallized for purification. Isopropanol and sodium chloride, AR grade, were obtained from Sinopharm Chemical Reagent Co. Ltd. (China) and used as received. The distilled water was used throughout the experiments.

The chemical shale stabilizer, SDCS, is an aluminum complex self-developed to impart shale stability. The aluminum complex could completely dissolve in the water-based drilling fluids when $\mathrm{pH}$ of the fluids is maintained above 11 . When interacting with formation water of low $\mathrm{pH}$, it could precipitate in the shale matrix and decrease the shale permeability, thus providing a barrier to pore pressure transmission. In addition, the chemical shale stabilizer could withstand high temperature and salt concentration.

The shale samples, here, were obtained from the Sichuan Basin, China. The main clay minerals of shale samples were determined to be illite/smectite and illite by X-ray diffraction analysis (Table 1), with cation exchange capacity and surface area of $40 \mathrm{mmol} / \mathrm{g}$ and $49.65 \mathrm{~m}^{2} / \mathrm{g}$, respectively. The cylindrical shale cores were used in the pore pressure transmission tests with a diameter of $2.54 \mathrm{~cm}$ and a length of $0.80 \mathrm{~cm}$.

2.2. Preparation of $P($ St $-M M A)$ Latex Particles. The $\mathrm{P}($ StMMA) latex particles were prepared by the emulsifier-free polymerization of styrene and methyl methacrylate using solvothermal method with potassium persulfate as an initiator in isopropanol-water medium. The styrene, methyl methacrylate, potassium persulfate, isopropanol, and distilled water of characteristic concentration were successively added into a hydrothermal synthesis reaction kettle. Then, the mixture above was stirred using electromagnetic stirring at room temperature for $15 \mathrm{~min}$ and at $90^{\circ} \mathrm{C}$ for another $2.5 \mathrm{~h}$. The $\mathrm{P}(\mathrm{St}-\mathrm{MMA})$ latex particles with different reaction conditions were prepared using similar methods. The recipes
TABLE 1: The mineralogical composition of shale samples.

\begin{tabular}{lc}
\hline X-ray diffraction & \% weight \\
\hline Quartz & 57 \\
K feldspar & 4 \\
Plagioclase & 6 \\
Siderite & 4 \\
Clay & 29 \\
Kaolinite & 14 \\
Chlorite & 12 \\
Illite & 36 \\
Illite/smectite & 38 \\
\hline
\end{tabular}

for synthesis of $\mathrm{P}(\mathrm{St}-\mathrm{MMA})$ latex particles were shown in Table 2.

2.3. Characterization of $P(S t-M M A)$ Latex Particles. The FT-IR spectra were acquired by using NEXUS 670 FT-IR spectrometer (Thermo Nicolet, USA), scanning from 4000 to $400 \mathrm{~cm}^{-1}$. The purified latex particles were dried under vacuum at $80^{\circ} \mathrm{C}$, and mixture of latex particles samples and potassium bromide $(\mathrm{KBr})$ was pressed into pellets for FT-IR analysis. The transmission electron microscopy (TEM) images of latex particles were taken with JEOL JEM2100UHR TEM using an accelerating voltage of $200 \mathrm{kV}$. The particle size distribution (PSD) of P(St-MMA) latex particles was analyzed with dynamic light scattering using Mastersizer 3000 (Malvern, UK). The samples of TEM and PSD were diluted before testing. The thermal gravimetric analysis (TGA) was conducted with a simultaneous thermal analyzer (NETZSCH, Germany) at a heating rate of 0 $50^{\circ} \mathrm{C} / \mathrm{min}$ under nitrogen atmosphere. It should be pointed out that the latex particles used for characterization were synthesized using S-3 recipe (Table 2).

2.4. Pore Pressure Transmission Tests. The pore pressure transmission test was developed using the pressure transmission technique to characterize the hydraulic properties of shale and the pore pressure transmission tests in this paper were performed on the simulation equipment for hydramechanics coupling of shale, developed by China University of Petroleum (East China) [23], and basic components of the simulation equipment are illustrated in Figure 1.

During the pore pressure transmission test, shale cores were subjected to hydraulic or osmotic gradients or both when exposed to upstream and downstream fluids. The confining pressure and axial pressure were all 5.0 $\mathrm{MPa}$ and upstream pressure was maintained at $3.0 \mathrm{MPa}$. The initial downstream pressure was $1.0 \mathrm{MPa}$. The pore pressure transmission tests were performed at $70^{\circ} \mathrm{C}$. The downstream pressure, namely, pore pressure, was monitored throughout the tests. With no chemical potential difference between upstream and downstream fluids, the downstream pressure would become equal to the applied constant fluids pressure at the upstream because of nonzero permeability of shale cores. But, when there is chemical potential difference present, any difference between the downstream pressure and the applied 
TABle 2: Recipes of the P(St-MMA) latex particles.

\begin{tabular}{|c|c|c|c|c|c|}
\hline Number & {$[\mathrm{St}]:[\mathrm{MMA}]$} & {$[\mathrm{KPS}] /(\mathrm{mmol} / \mathrm{L})$} & $V$ (isopropanol) $: V$ (water) & Temperature $\left({ }^{\circ} \mathrm{C}\right)$ & Time $(\mathrm{h})$ \\
\hline S-1 & $1: 1$ & 7.40 & $2: 3$ & 70 & 2.5 \\
\hline S-2 & $1: 1$ & 7.40 & $2: 3$ & 80 & 2.5 \\
\hline S-3 & $1: 1$ & 7.40 & $2: 3$ & 90 & 2.5 \\
\hline S-4 & $1: 1$ & 7.40 & $2: 3$ & 100 & 2.5 \\
\hline S-5 & $1: 1$ & 7.40 & $2: 3$ & 90 & 2.0 \\
\hline S-6 & $1: 1$ & 7.40 & $2: 3$ & 90 & 3.0 \\
\hline S-7 & $1: 1$ & 7.40 & $2: 3$ & 90 & 3.5 \\
\hline S-8 & $1: 1$ & 7.40 & $2: 3$ & 90 & 4.0 \\
\hline S-9 & $1: 1$ & 7.40 & $1: 4$ & 90 & 2.5 \\
\hline S-10 & $1: 1$ & 7.40 & $3: 7$ & 90 & 2.5 \\
\hline S-11 & $1: 1$ & 7.40 & $1: 1$ & 90 & 2.5 \\
\hline S-13 & $1: 1$ & 5.40 & $2: 3$ & 90 & 2.5 \\
\hline S-14 & $1: 1$ & 6.40 & $2: 3$ & 90 & 2.5 \\
\hline S-15 & $1: 1$ & 10.40 & $2: 3$ & 90 & 2.5 \\
\hline
\end{tabular}

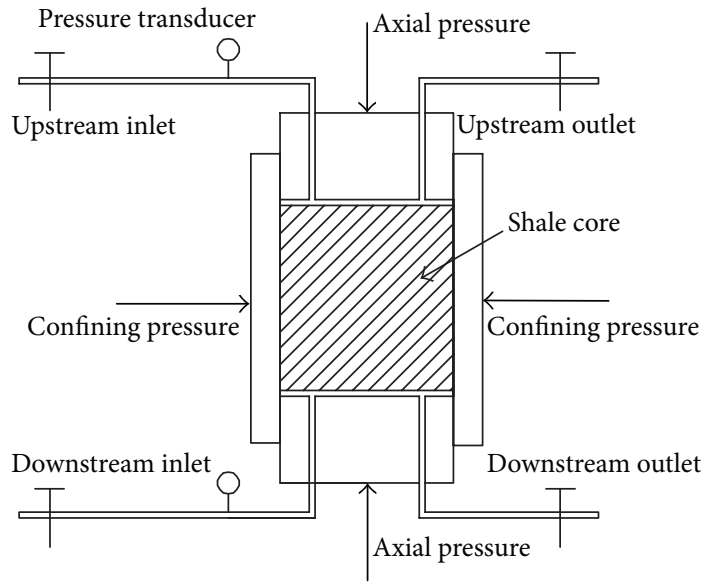

FIGURE 1: Schematic of pore pressure transmission test setup.

constant fluid pressure could be measured in response to osmotic pressure.

The permeability of shale cores could be calculated using formula (1) [24]. Consider

$$
\begin{aligned}
K= & \frac{\mu \beta V L}{A} \\
\times & \left(\ln \left(\frac{P_{m}-P_{0}}{P_{m}-P\left(L, t_{2}\right)}\right)-\ln \left(\frac{P_{m}-P_{0}}{P_{m}-P\left(L, t_{1}\right)}\right)\right) \\
& \times\left(t_{2}-t_{1}\right)^{-1},
\end{aligned}
$$

where $K$ is the permeability of shale cores, $\mu \mathrm{m}^{2} ; \mu$ is the viscosity of fluids, mPa.s; $\beta$ is the static compression ratio of fluids, $\mathrm{MPa}^{-1} ; V$ is the enclosed volume of downstream fluids, $\mathrm{cm}^{3} ; L$ is the length of shale cores, $\mathrm{cm} ; A$ is the cross-sectional area, $\mathrm{cm}^{2} ; t$ is total experimental time, $\mathrm{s} ; P_{m}$ is the upstream pressure, $\mathrm{MPa} ; P_{0}$ is the pore pressure, $\mathrm{MPa} ; P(L, t)$ is the realtime downstream pressure, $\mathrm{MPa}$.
Shale could act as a nonideal semipermeable membrane, and membrane efficiency was defined as the ratio of actual osmotic pressure and ideal osmotic pressure to characterize its nonideality [25]. Consider

$$
\sigma=\frac{\Delta P}{\Delta \Pi}=\frac{\Delta P}{\left(R T / V_{W}\right) \ln \left(a_{w}^{\mathrm{sh}} / a_{w}^{\mathrm{df}}\right)},
$$

where $\sigma$ is the membrane efficiency of shale cores, \%; $\Delta P$ is the actual osmotic pressure, $\mathrm{MPa}$; $R$ is the ideal gas constant, $8.314 \mathrm{~J} \cdot \mathrm{mol}^{-1} \cdot \mathrm{K}^{-1} ; T$ is the test temperature, $\mathrm{K} ; V_{W}$ is the partial molar volume of water, $18 \mathrm{~cm}^{3} \cdot \mathrm{mol}^{-1} ; a_{w}^{\text {sh }}$ is the water activity of pore water; $a_{w}^{\mathrm{df}}$ is the water activity of drilling fluids.

In addition, the pore structure of shale cores before and after tests was characterized by Hitachi S- 4800 field-emission scanning electron microscope (SEM) analysis.

\section{Results and Discussion}

\subsection{Characterization of $P(S t-M M A)$ Latex Particles}

3.1.1. FT-IR Analysis. The FT-IR spectrum of purified latex particles (Figure 2) showed absorption peak at around $1730 \mathrm{~cm}^{-1}$, corresponding to the $\mathrm{C}=\mathrm{O}$ stretching band, and two characteristic absorption peaks at around $1236 \mathrm{~cm}^{-1}$ and $1142 \mathrm{~cm}^{-1}$, corresponding to the $\mathrm{C}-\mathrm{O}-\mathrm{C}$ symmetric stretching band. The stretching vibrations of benzene skeleton were presented at around $1601 \mathrm{~cm}^{-1}, 1489 \mathrm{~cm}^{-1}$, and $1454 \mathrm{~cm}^{-1}$, and $754 \mathrm{~cm}^{-1}$ and $700 \mathrm{~cm}^{-1}$ were characteristic bending vibrations of single substitution benzene ring. It was also observed from Figure 2 that the $\mathrm{C}-\mathrm{H}$ absorption peaks of single substitution benzene ring were found at $3093 \mathrm{~cm}^{-1}$, $3065 \mathrm{~cm}^{-1}, 3020 \mathrm{~cm}^{-1}$, and $2996 \mathrm{~cm}^{-1}[26,27]$. Because the $\mathrm{P}(\mathrm{St})$ and $\mathrm{P}(\mathrm{MMA})$ have been separated before testing, the above discussion confirmed that the newly synthesized latex particles were copolymers of St and MMA. 


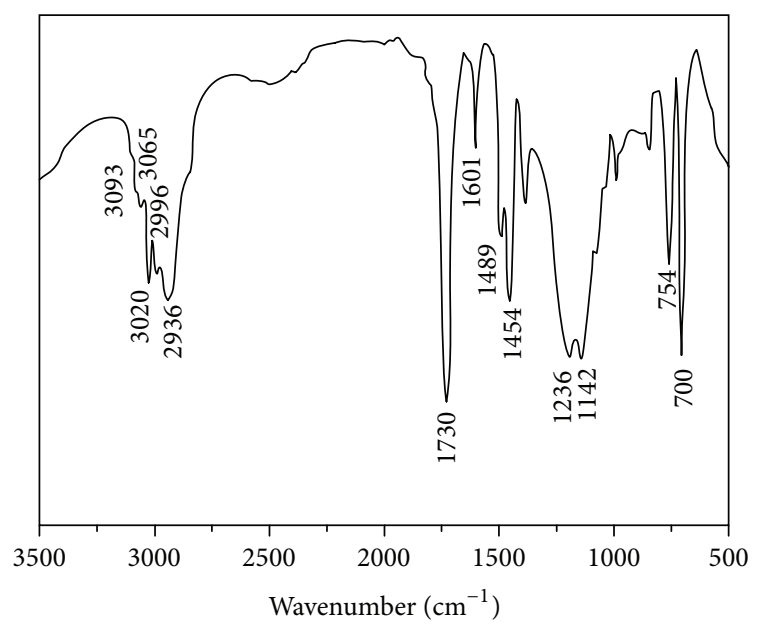

FIGURE 2: FT-IR spectrum of purified latex particles.

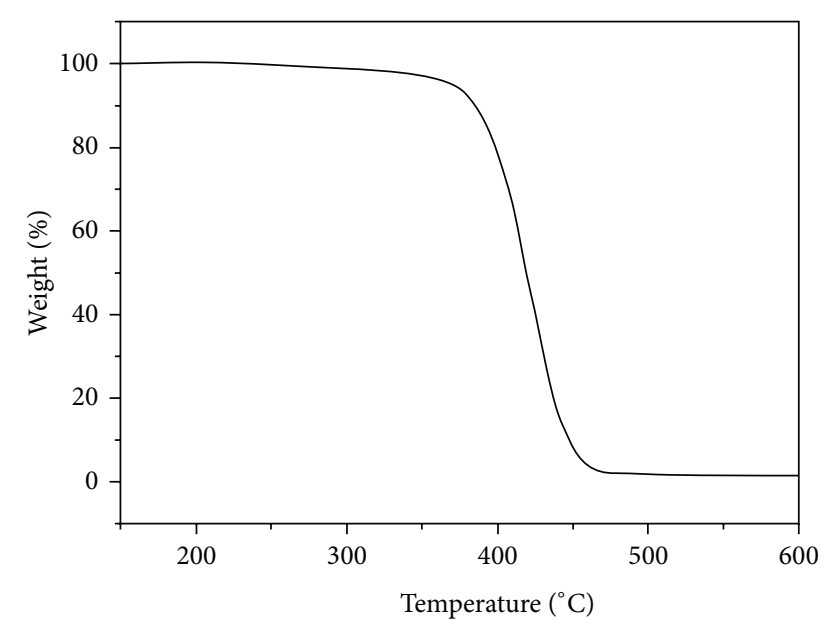

FIGURE 3: TGA curve of purified latex particles.

3.1.2. TGA Analysis. The weight loss observed up to $200^{\circ} \mathrm{C}$ was attributed to the desorption of physically absorbed water and dehydration of the hydrated cations. The organic compounds were decomposed between 200 and $500^{\circ} \mathrm{C}$ [28]. From the TGA curve (Figure 3), the purified latex particles began to decompose at around $250^{\circ} \mathrm{C}$ and the weight loss of latex particles would not increase significantly until temperature increased up to $380^{\circ} \mathrm{C}$, indicating that the newly synthesized latex particles maintain good thermal stability. This can be attributed to the fact that the rigidity of $\mathrm{P}(\mathrm{St}-\mathrm{MMA})$ is enhanced owing to the introduction of benzene ring [29].

3.1.3. PSD and TEM Analysis. As can be seen from Figure 4, the particle size of latex particles almost unimodally distributed from $80 \mathrm{~nm}$ to $345 \mathrm{~nm}$ with the D90 value of $276 \mathrm{~nm}$ in addition to some aggregates with larger sizes. After entering pore throats and microfractures of shale, the coarse particles are prone to bridge or seal the largest openings of shale formation and finer particles are necessary to fill the voids between coarse particles to produce a tight immobile

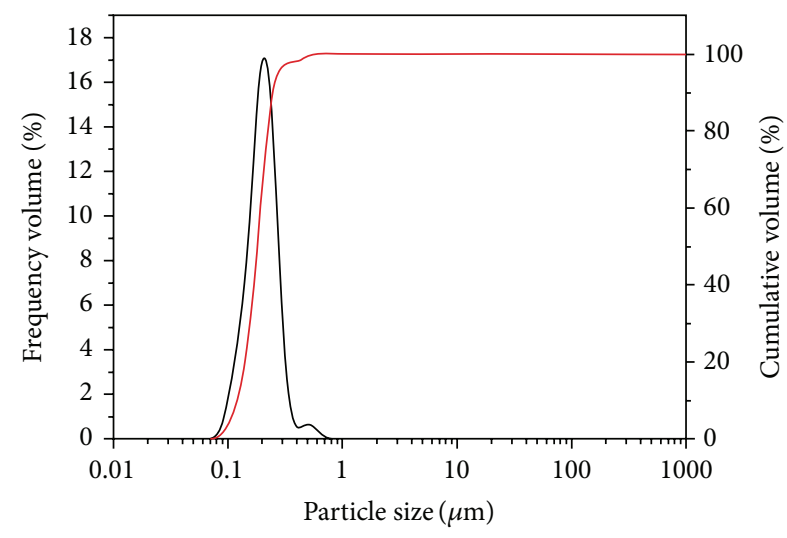

Figure 4: Particle size distribution of latex particles.

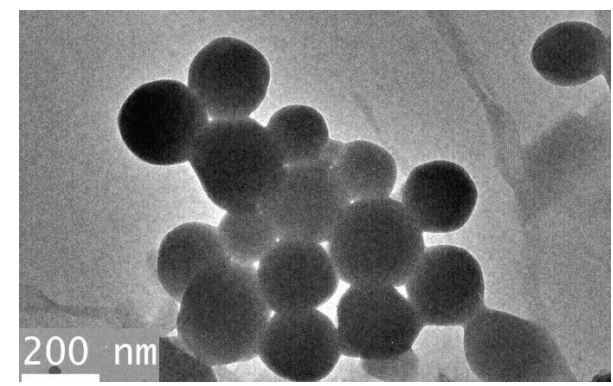

FIGURE 5: TEM micrograph of latex particles.

plug [30]. Figure 5 displays the representative TEM micrograph of $\mathrm{P}(\mathrm{St}-\mathrm{MMA})$ latex particles. It can be seen that the latex particles are spherical and the average particle size determined by TEM is about $200 \mathrm{~nm}$, which is consistent with the $\mathrm{D} 50$ value $(208 \mathrm{~nm})$ of PSD analysis.

3.2. Factors Influencing PSD of P(St-MMA) Latex Particles. When it comes to reducing shale pore pressure transmission, particle size distribution is one of the most important factors influencing plugging mechanism and efficiency of pore throats and microfractures $[31,32]$, and D90, cumulative amount of $90 \%$ of particles which are smaller than the size, is commonly defined as a characteristic parameter. Thus, the effects of isopropanol volume, reacting temperature, and initiator concentration on particle size distribution (PSD) of latex particles were discussed here.

3.2.1. Isopropanol Volume. It can be seen from Figure 6 that the D90 value of latex particles decreased continuously with the increase of isopropanol volume from $10 \%$ to $50 \%$. This can be attributed to the fact that, owing to the introduction of isopropanol, the reacting medium has lower polarity and surface tension, and it is beneficial to dispersion of droplets or particles. Additionally, isopropanol acts as chain transfer agent in the polymerization, and it could generate more surface-active oligomers in the nucleation stage and prevent particles aggregation, thus decreasing the latex particle size [33]. 


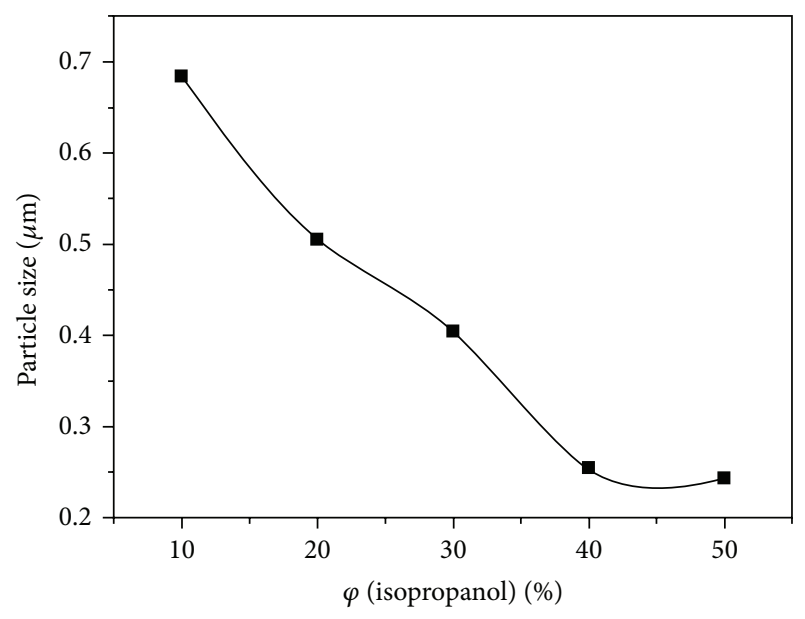

FIGURE 6: Effect of isopropanol volume on D90.

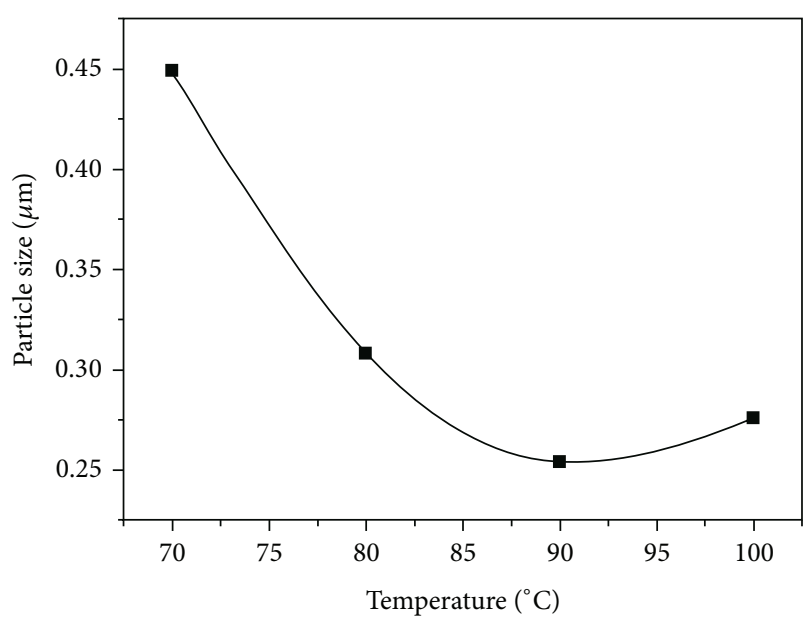

FIGURE 7: Effect of reacting temperature on D90.

3.2.2. Reacting Temperature. The effect of reacting temperature on D90 value of latex particles is shown in Figure 7. It can be seen that the D90 value of latex particles decreased with the increase of reacting temperature, but when reacting temperature exceeded $90^{\circ} \mathrm{C}$, the $\mathrm{D} 90$ value began to increase with the increase of reacting temperature. This can be attributed to two aspects. On the one hand, high reacting temperature increases the solubility of monomers and decomposition rate of initiators and generates more latex particles in the nucleation stage, thus decreasing the latex particle size. On the other hand, high reacting temperature could also intensify the Brownian motion and deteriorate dispersion stability of latex particles. Additionally, due to hydrophobic hydration effect and pressure effect on solubility of hydrophobic monomers, the increase of reacting temperature would also enhance the coalescence of oligomer micelle, thus increasing the latex particle size $[34,35]$.

3.2.3. Initiator Concentration. Figure 8 depicts the effect of initiator concentration on D90 value of latex particles. It can be seen that the D90 value of latex particles decreased

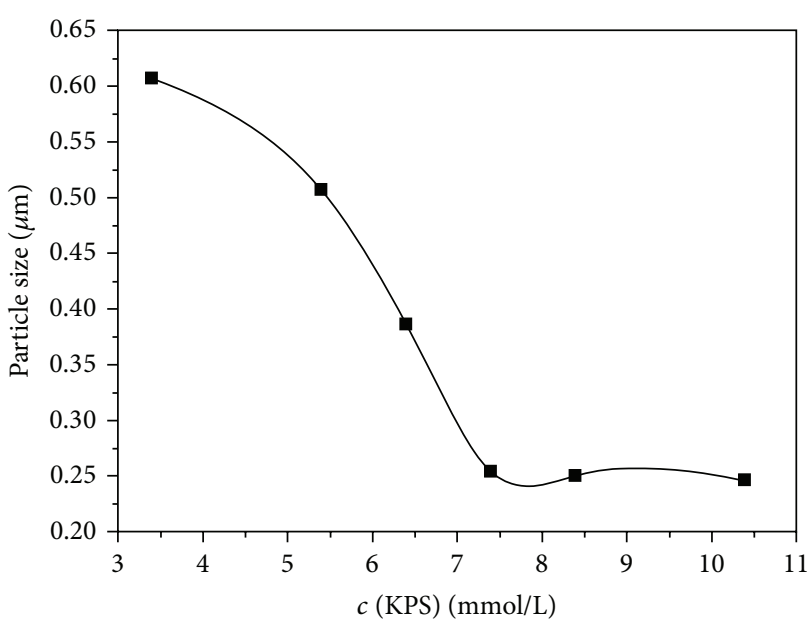

FIGURE 8: Effect of initiator concentration on D90.

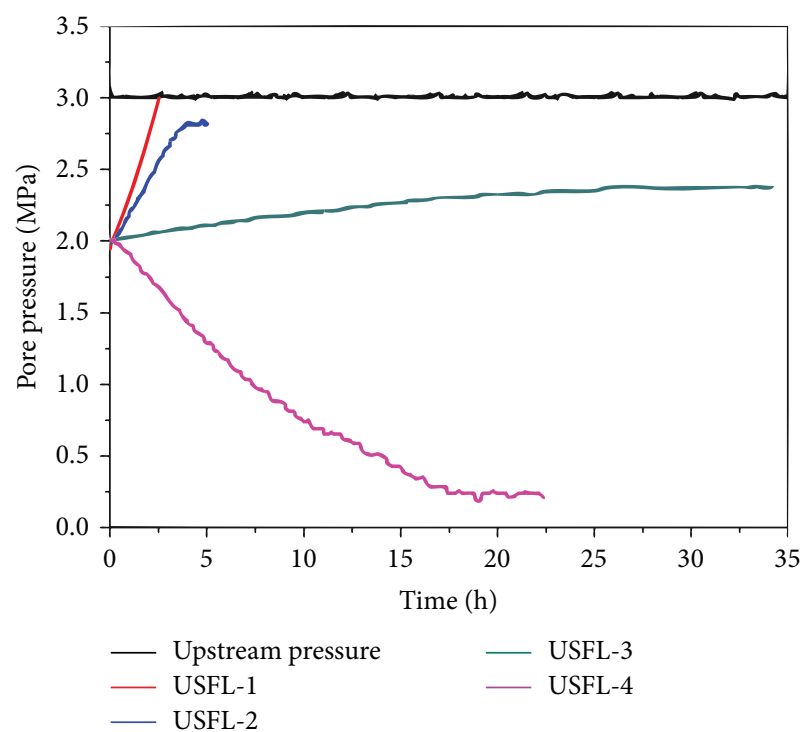

FIgURE 9: Pore pressure transmission test curves.

with the increase of initiator concentration, and when the initiator concentration exceeded $7.4 \mathrm{mmol} / \mathrm{L}$, the $\mathrm{D} 90$ value would not decrease any longer. The increase of initiator concentration makes it beneficial to generate more negatively charged surface-active oligomer micelles that are absorbed on latex particles, thus preventing latex particles aggregation and decreasing latex particles size. The high initiator concentration could also accelerate nucleation rate and polymerization rate because of high free radical production.

3.3. Pore Pressure Transmission Tests. During the pore pressure transmission tests, the $\mathrm{P}($ St-MMA) latex particles were used as physical shale stabilizer (SDPS) and self-developed aluminum complex was used as chemical shale stabilizer (SDCS). The downstream fluid was 3\% sodium chloride solution (DSFL, $a_{w}=0.998$ ), and the upstream fluids were $3 \%$ sodium chloride solution (USFL-1, $a_{w}=0.998$ ), $20 \%$ sodium chloride solution (USFL-2, $a_{w}=0.875$ ), $3 \%$ sodium chloride 


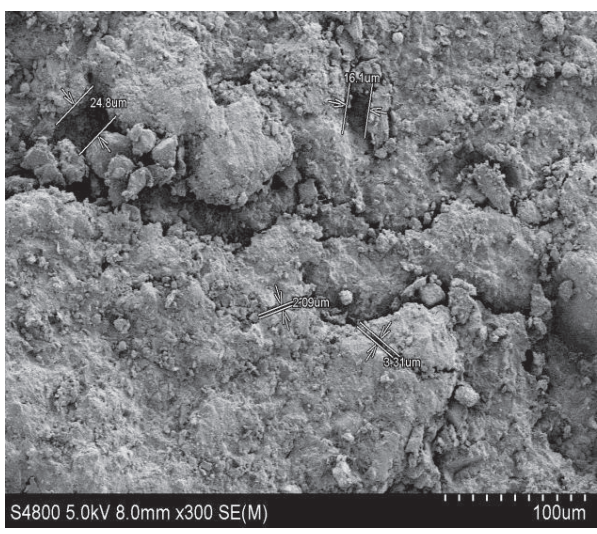

(a)

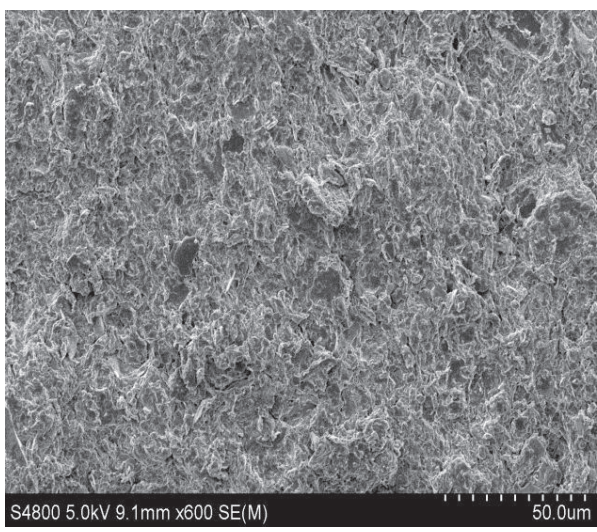

(c)

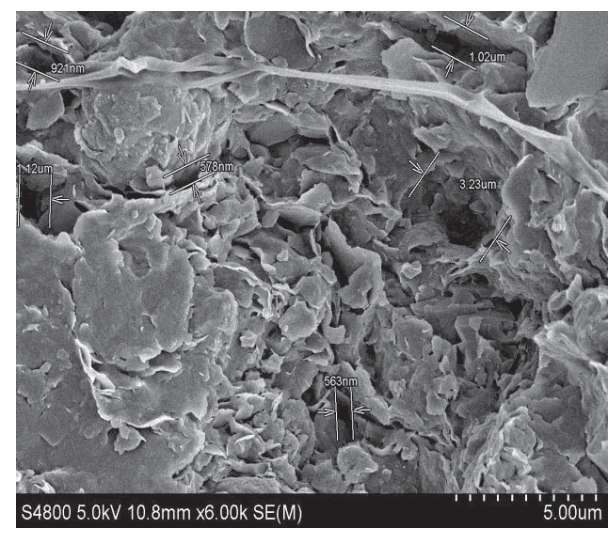

(b)

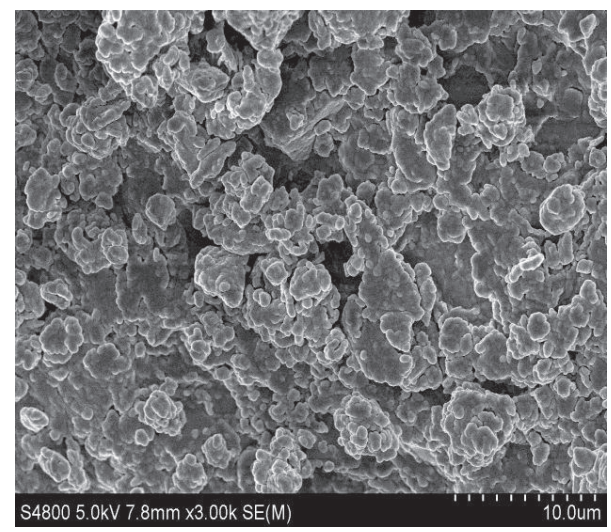

(d)

FIGURE 10: SEM photographs of shale cores: (a)-(b) natural shale cores; (c)-(d) shale cores after interacting with USFL-4.

solution with $3 \%$ SDPS (USFL-3, $a_{w}=0.998$ ), $20 \%$ sodium chloride solution with $2 \%$ SDPS, and $1 \%$ SDCS (USFL- $4, a_{w}=$ $0.875)$, respectively.

The curves of pore pressure transmission tests are shown in Figure 9. It can be concluded that it takes more time for pore pressure build-up under hydraulic pressure when interacting with USFL-3. The permeability of shale cores could be calculated according to formula (1). After interacting with USFL-3, the permeability decreased significantly from $1.26 \times 10^{-7} \mu \mathrm{m}^{2}$ (USFL-1) to $1.01 \times 10^{-8} \mu \mathrm{m}^{2}$. Because there is no chemical potential difference between USFL-1/USFL-3 and DSFL, the effect of preventing or reducing pore pressure transmission is mainly related to internally bridging and sealing shale microfractures of deformable P(St-MMA) latex particles.

When the upstream fluid was changed to $20 \%$ sodium chloride solution (USFL-2, $a_{w}=0.875$ ), the pore pressure (downstream pressure) would be less than upstream pressure due to chemical potential difference between USFL-2 and DSFL. After interacting with USDL-4, the downstream pressure decreased gradually and offset the hydraulic pressure. It is concluded that shale acts as a semipermeable membrane, and the hydraulic pressure could be offset by the backflow caused by the development of osmosis when there exists chemical potential difference. According to formula (2), the membrane efficiency of natural shale core is only $1.61 \%$, and it increases to $14.71 \%$ after interacting with USDL-4.

As shown in Figure 10, the P(St-MMA) latex particles could be deformable to internally bridge and seal pore throats and microfractures of shale cores, and the aluminum complex would precipitate when the drilling fluid filtrate is exposed to formation water and the precipitation could block and seal pore throats and microfractures [36]. What is more, the P(St-MMA) latex particles and aluminum complex could act synergistically to reduce pore pressure transmission and increase membrane efficiency of shale cores, thus improving shale stability in drilling engineering.

\section{Conclusions}

The P(St-MMA) latex particles have been successfully prepared by emulsifier-free emulsion polymerization of $\mathrm{St}$ and MMA, using potassium persulfate as an initiator in isopropanol-water medium. The latex particles possessed unimodal distribution from $80 \mathrm{~nm}$ to $345 \mathrm{~nm}$ with the D90 value of $276 \mathrm{~nm}$, and the particle size was influenced significantly by isopropanol volume, reacting temperature, and initiator concentration. The latex particles could disperse uniformly in the water-based drilling fluids as potential physical shale stabilizer and they could be deformable to 
internally bridge and seal pore throats and microfractures of shale. What is more, a cooperative action was observed in $\mathrm{P}($ St-MMA) latex particles (physical shale stabilizer) and aluminum complex (chemical shale stabilizer) to reduce pore pressure transmission and increase membrane efficiency of shale, thus improving shale wellbore stability. The newly synthesized latex particles were alternatives to conventional plugging agents in water-based drilling fluids for shale gas.

\section{Conflict of Interests}

The authors declare that there is no conflict of interests regarding the publication of this paper.

\section{Acknowledgments}

The authors would like to acknowledge the financial support from the National Science and Technology Major Project of China (2011ZX05005-006-007HZ) and the Graduate Innovation Project of China University of Petroleum (East China) (YCX2014006).

\section{References}

[1] K. A. Bowker, "Recent development of the Barnett Shale play, Fort Worth Basin: West Texas," Geological Society Bulletin, vol. 42, no. 6, pp. 1-11, 2003.

[2] C. N. Zou, R. K. Zhu, B. Bai et al., "First discovery of nano-pore throat in oil and gas reservoir in China and its scientific value," Acta Petrologica Sinica, vol. 27, no. 6, pp. 1857-1864, 2011.

[3] H. B. Tan, Y. Z. Li, H. F. Tuo, M. Zhou, and B. Tian, "Experimental study on liquid/solid phase change for cold energy storage of liquefied natural gas (LNG) refrigerated vehicle," Energy, vol. 35, no. 5, pp. 1927-1935, 2010.

[4] H. F. Tuo, "Thermal-economic analysis of a transcritical Rankine power cycle with reheat enhancement for a low-grade heat source," International Journal of Energy Research, vol. 37, no. 8, pp. 857-867, 2013.

[5] C. R. Clarkson, J. L. Jensen, and T. A. Blasingame, "Reservoir engineering for unconventional gas reservoirs: what do we have to consider?" in Proceedings of the North American Unconventional Gas Conference and Exhibition, SPE Paper 145080, pp. 936-980, Woodlands, Tex, USA, June 2011.

[6] E. van Oort, A. H. Hale, F. K. Mody, and S. Roy, “Transport in shales and the design of improved water-based shale drilling fluids," SPE Journal, vol. 11, no. 3, pp. 137-146, 1996.

[7] E. van Oort, "Physico-chemical stabilization of shales," in Proceedings of the International Symposium on Oilfield Chemistry, SPE Paper 37263, pp. 523-538, Houston, Tex, USA, February 1997.

[8] U. Tare and F. Mody, "Stabilizing boreholes while drilling reactive shales with silicate-base drilling fluids," Drilling Contract, vol. 5-6, pp. 42-44, 2000.

[9] J. C. Rojas, D. E. Clark, B. Greene, and J. G. Zhang, "Optimized salinity delivers improved drilling performance," in Proceedings of the AADE Fluids Conference, AADE-06-DF-HO-11, Houston, Tex, USA, April 2006.

[10] Z. S. Qiu, J. F. Xu, K. H. Lv et al., "A multivariate cooperation principle for wellbore stabilization," Acta Petrologica Sinica, vol. 27, no. 2, pp. 26-27, 2005.
[11] J. Y. Liu, Z. S. Qiu, W. A. Huang et al., "Experimental study on wellbore stability of fractured shale," Eastern European Summer Time A: Energy Science and Research, vol. 32, no. 2, pp. 1213-1218, 2014.

[12] M. Ramirez, D. Clapper, and P. Kenny, "Drilling-fluid design for challenging wells in the Andean Mountain region," in Proceedings of the SPE Annual Technical Conference and Exhibition, SPE Paper 102206, San Antonio, Tex, USA, September 2006.

[13] S. Benaissa, D. K. Clapper, B. Hughes, P. Parigot, and D. Degouy, "Oil field applications of aluminum chemistry and experience with aluminum-based drilling fluid additive," in Proceedings of the SPE International Symposium on Oilfield Chemistry, SPE Paper 37268, Houston, Tex, USA, February 1997.

[14] R. J. Ambrose, R. C. Hartman, M. Diaz-Campos, I. Y. Akkutlu, and C. Sondergeld, "New pore-scale considerations for shale gas in place calculations," in Proceedings of the SPE Unconventional Gas Conference, SPE Paper 131772, Pittsburgh, Pa, USA, February 2010.

[15] C. R. Clarkson, N. Solano, R. M. Bustin et al., "Pore structure characterization of North American shale gas reservoirs using USANS/SANS, gas adsorption, and mercury intrusion," Fuel, vol. 103, pp. 606-616, 2013.

[16] C. R. Clarkson, J. M. Wood, S. D. Aquino, S. E. Burgis, M. Freeman, and V. Birss, "Nanopore structure analysis and permeability predictions for a tight gas/shale reservoir using low-pressure adsorption and mercury intrusion techniques," in Proceedings of the SPE Americas Unconventional Resources Conference, Pittsburgh, Pa, USA, June 2012, SPE Paper 155537.

[17] X.-J. Song, J. Hu, and C.-C. Wang, "Synthesis of highly surface functionalized monodispersed poly(St/DVB/GMA) nanospheres with soap-free emulsion polymerization followed by facile "click chemistry" with functionalized alkylthiols," Colloids and Surfaces A: Physicochemical and Engineering Aspects, vol. 380, no. 1-3, pp. 250-256, 2011.

[18] R. L. Li, C. Y. Kan, Z. P. Li, Y. Du, and Y. N. Cui, "Preparation of multihollow P(St-MAA) particles by sequence soap-free/soap emulsion polymerization and followed by stepwise alkali/acid posttreatment," Chinese Chemical Letters, vol. 18, no. 6, pp. 741743, 2007.

[19] G. Kim, S. Lim, B. H. Lee, S. E. Shim, and S. Choe, "Effect of homogeneity of methanol/water/monomer mixture on the mode of polymerization of MMA: soap-free emulsion polymerization versus dispersion polymerization," Polymer, vol. 51, no. 5, pp. 1197-1205, 2010.

[20] P. Bataille, M. Almassi, and M. Inoue, "Emulsifier-free emulsion polymerization of N-butyl methacrylate," Journal of Applied Polymer Science, vol. 67, no. 10, pp. 1711-1719, 1998.

[21] R. Yan, Y. Y. Zhang, X. H. Wang, J. Xu, D. Wang, and W. Zhang, "Synthesis of porous poly(styrene-co-acrylic acid) microspheres through one-step soap-free emulsion polymerization: whys and wherefores," Journal of Colloid and Interface Science, vol. 368, no. 1, pp. 220-225, 2012.

[22] H. Q. Wu, Q. Y. Wang, D. M. Xu et al., "Preparation of emulsifier-free cationic poly (methylmethacrylate-styrene) nanoparticles latex by solvotheraml method," Chinese Journal of Synthetic Chemistry, vol. 15, no. 6, pp. 693-696, 2007.

[23] J. F. Xu and Z. S. Qiu, "Simulation test equipment of coupled hydra-mechanics of shales," Journal of China University of Petroleum (Edition of Natural Science), vol. 30, no. 3, pp. 63-66, 2006.

[24] J.-F. Xu, Z.-S. Qiu, and K.-H. Lü, “Pressure transmission testing technology and simulation equipment for hydra-mechanics 
coupling of shale," Acta Petrolei Sinica, vol. 26, no. 6, pp. 115118, 2005.

[25] M. A. Ramirez, D. K. Clapper, and G. Sanchez, "Aluminumbased HPWBM successfully replace oil-based mud to drill exploratory wells in environmentally sensitive area," in Proceedings of the SPE Latin American and Caribbean Petroleum Engineering Conference, SPE Paper 94437, Rio de Janeiro, Brazil, June 2005.

[26] W. Jiang, J. A. Joens, D. D. Dionysiou, and K. E. O’Shea, "Optimization of photocatalytic performance of $\mathrm{TiO}_{2}$ coated glass microspheres using response surface methodology and the application for degradation of dimethyl phthalate," Journal of Photochemistry and Photobiology A: Chemistry, vol. 262, pp. 713, 2013.

[27] W. Jiang, M. Pelaez, D. D. Dionysiou, M. H. Entezari, D. Tsoutsou, and K. O'Shea, "Chromium(VI) removal by maghemite nanoparticles," Chemical Engineering Journal, vol. 222, no. 15, pp. 527-533, 2013.

[28] A. K. Barick and D. K. Tripathy, "Thermal and dynamic mechanical characterization of thermoplastic polyurethane/ organoclay nanocomposites prepared by melt compounding," Materials Science and Engineering A, vol. 527, no. 3, pp. 812-823, 2010.

[29] R. Q. Bai, T. Qiu, F. Han, L. He, and X. Li, "Preparation and characterization of emulsifier-free polyphenylsilsesquioxane-poly (styrene-butyl acrylate) hybrid particles," Applied Surface Science, vol. 282, pp. 231-235, 2013.

[30] H. Soroush and J. H. B. Sampaio, "Investigation into strengthening methods for stabilizing wellbores in fractured formations," in Proceedings of the SPE Annual Technical Conference and Exhibition, San Antonio, Tex, USA, September 2006, SPE Paper 101802.

[31] N. Kaageson-Loe, M. W. Sanders, F. Growcock et al., "Particulate based loss-prevention material-the secrets of fracture sealing revealed," in Proceedings of the IADC/SPE Drilling Conference, SPE Paper 112595, Orlando, Fla, USA, March 2008.

[32] A. Dick, T. J. Heinz, C. F. Svoboda et al., "Optimizing the selection of bridging particles for reservoir drilling fluids," in Proceedings of the SPE International Symposium on Formation Damage, SPE Paper 58793, Lafayette, La, USA, February 2000.

[33] H. Dong, H. Q. Wu, Q. Y. Wang et al., "Preparation of emulsifierfree poly (St-MMA) nanoparticles latex by solvotheraml method," Chinese Journal of Synthetic Chemistry, vol. 15, no. 3, pp. 330-333, 2007.

[34] N. Baden, O. Kajimoto, and K. Hara, "High-pressure studies on aggregation number of surfactant micells using fluorescence quenching method," Journal of Physical Chemistry B, vol. 106, no. 34, pp. 8621-8624, 2002.

[35] N. T. Southall, K. A. Dill, and A. D. J. Haymet, "A view of the hydrophobic effect," Journal of Physical Chemistry B, vol. 106, no. 3, pp. 521-533, 2002.

[36] S. F. Zhang, Z. S. Qiu, W. A. Huang, J. Cao, and X. Luo, "Characterization of a novel aluminum-based shale stabilizer," Journal of Petroleum Science and Engineering, vol. 103, pp. 36-40, 2013. 

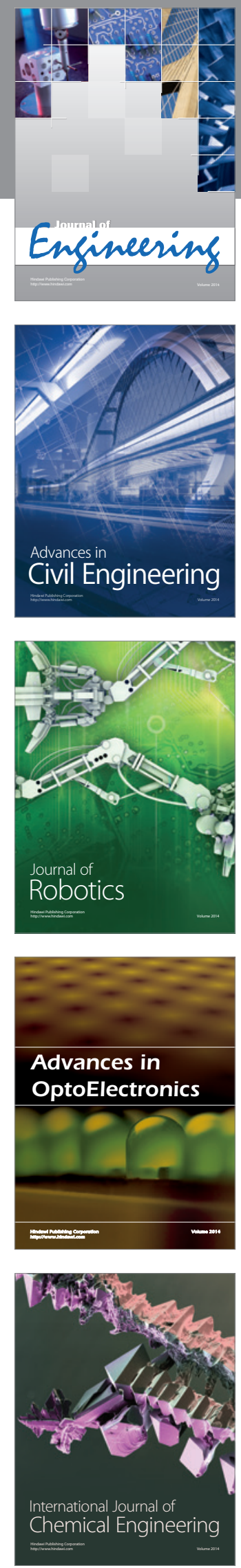

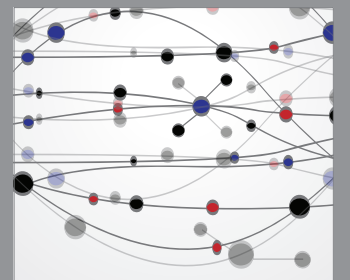

The Scientific World Journal
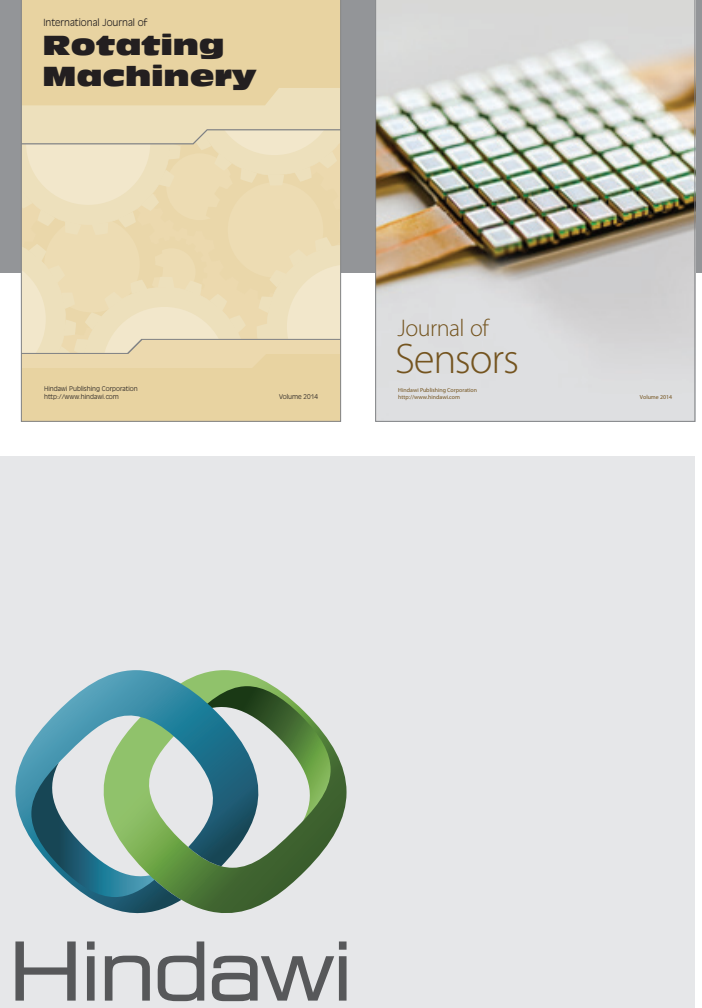

Submit your manuscripts at http://www.hindawi.com
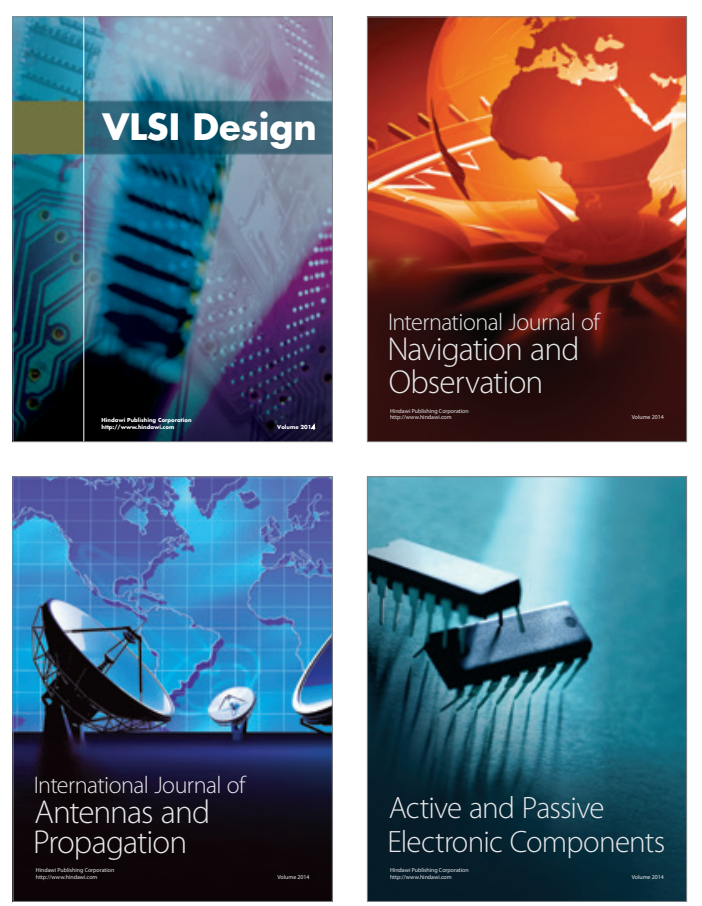
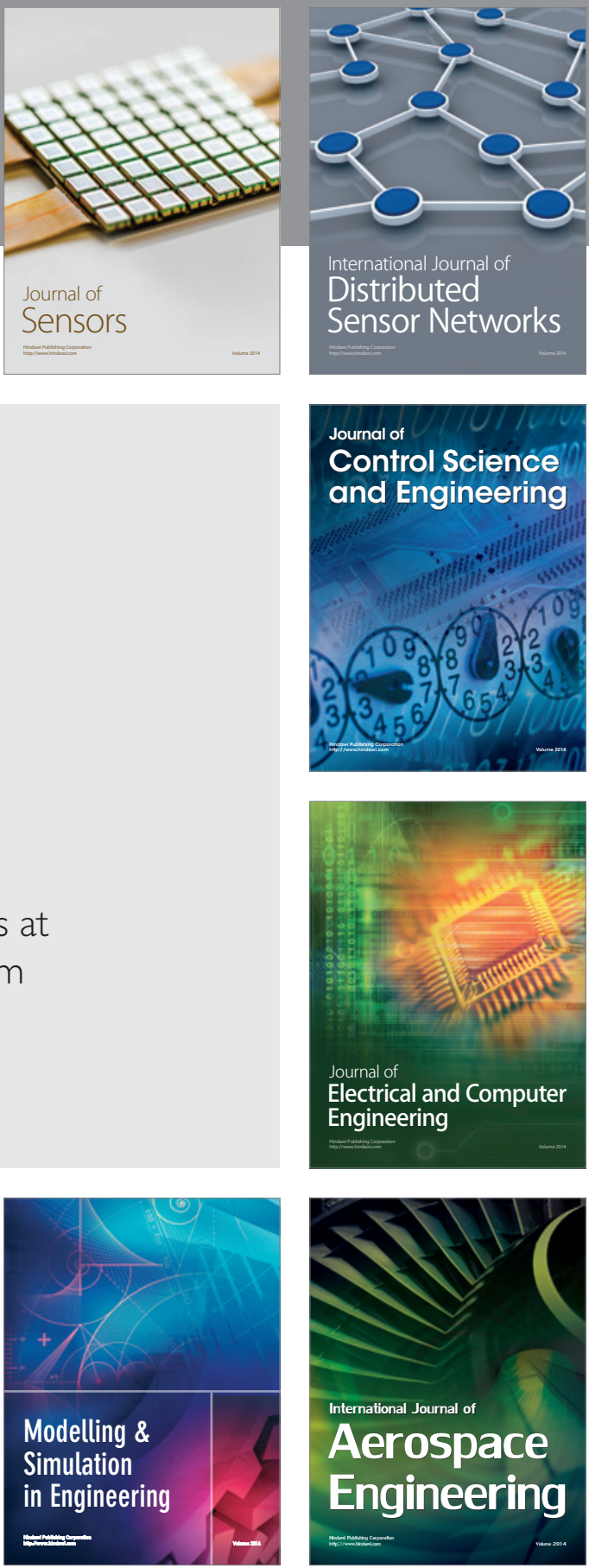

Journal of

Control Science

and Engineering
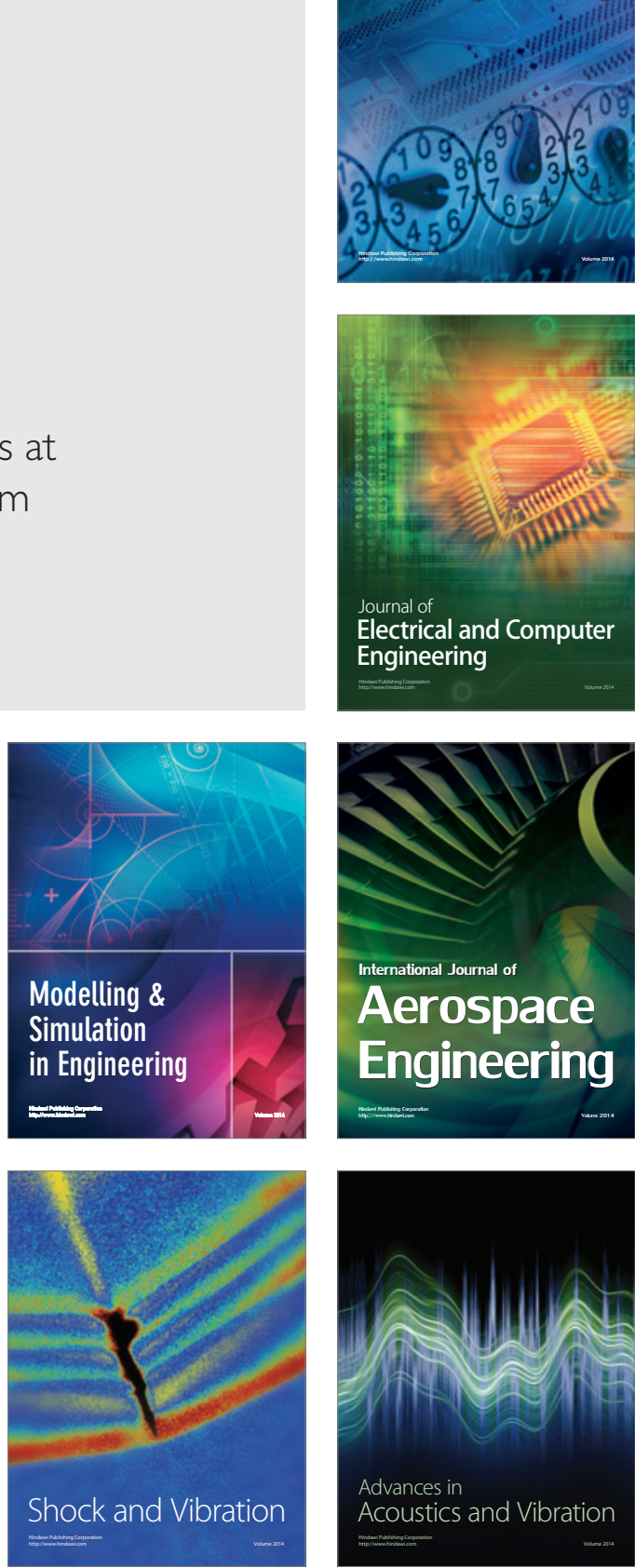